\title{
Ketjenblack Carbon Supported Amorphous Manganese Oxides Nanowires as Highly Efficient Electrocatalyst for Oxygen Reduction Reaction in Alkaline Solutions
}

\author{
Jang-Soo Lee, ${ }^{\dagger}$ Gi Su Park, ${ }^{\dagger}$ Ho Il Lee, ${ }^{\ddagger}$ Sun Tai Kim, ${ }^{\dagger}$ Ruiguo Cao, ${ }^{\dagger}$ Meilin Liu, ${ }^{*, \S}$ and Jaephil Cho*, \\ ${ }^{+}$Interdisciplinary School of Green Energy, Ulsan National Institute of Science and Technology (UNIST), Ulsan, 689-798, Korea \\ ${ }^{\ddagger}$ Energy Research Department, Industrial Research Institute, R \& D Division, Hyundai Heavy Industries Co., Ltd., 682-792, Korea \\ ${ }^{\S}$ School of Materials Science and Engineering, Georgia Institute of Technology, Atlanta, Georgia 30332-0245, United States
}

Supporting Information

\section{ABSTRACT:}
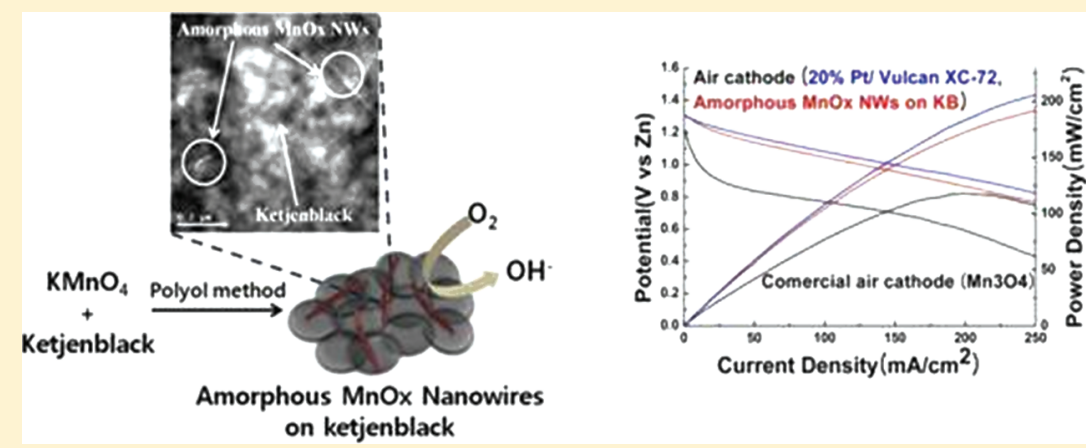

A composite air electrode consisting of Ketjenblack carbon $(\mathrm{KB})$ supported amorphous manganese oxide (MnOx) nanowires, synthesized via a polyol method, is highly efficient for the oxygen reduction reaction (ORR) in a $\mathrm{Zn}$-air battery. The low-cost and highly conductive $\mathrm{KB}$ in this composite electrode overcomes the limitations due to low electrical conductivity of $\mathrm{MnOx}$ while acting as a supporting matrix for the catalyst. The large surface area of the amorphous MnOx nanowires, together with other microscopic features (e.g., high density of surface defects), potentially offers more active sites for oxygen adsorption, thus significantly enhancing ORR activity. In particular, a $\mathrm{Zn}$ - air battery based on this composite air electrode exhibits a peak power density of $\sim 190 \mathrm{~mW} / \mathrm{cm}^{2}$, which is far superior to those based on a commercial air cathode with $\mathrm{Mn}_{3} \mathrm{O}_{4}$ catalysts.

KEYWORDS: Oxygen reduction reaction, amorphous manganese oxide nanowire, Ketjenblack carbon, electrical conductivity, $\mathrm{Zn}$-air battery

R atteries with higher energy density are needed to meet the Bever-increasing demands of many emerging technologies, from portable electronics to electrical vehicles. The energy densities of the existing batteries are limited primarily by the low energy density of electrode materials used. To dramatically enhance the energy density of batteries, considerable efforts have been devoted to the development of new air electrodes for efficient utilization of oxygen from air in metal-air batteries. Among many metals that may be used as the anode (e.g., Ca, Al, $\mathrm{Fe}, \mathrm{Cd}, \mathrm{Li}$, and $\mathrm{Zn}$ ) in a metal-air battery, $\mathrm{Zn}$ metal has received much attention due to its low cost, abundance, and environmental benignity. Additional advantages of $\mathrm{Zn}$-air batteries include a flat discharge voltage and a long shelf life. ${ }^{1}$ To date, however, the performance of a $\mathrm{Zn}$-air battery is limited largely by the poor performance of the air electrode because the rate of the oxygen reduction reaction (ORR) is much slower than that of zinc oxidation. (See Figure S1 in the Supporting Information). Thus, the development of efficient catalyst for accelerating ORR in an air electrode is vital to achieving high-performance zinc-air batteries.

Nanoparticles of precious metals and alloys with wellcontrolled facets are reported active and efficient catalysts for ORR in fuel cells and metal-air batteries. ${ }^{2}$ However, their high cost and scarcity severely hinder their applicability to broad commercialization. Accordingly, transition metal oxides and other less expensive catalysts have been used as alternative ORR catalysts in primary alkaline based fuel cells and metal-air batteries. ${ }^{3}$ Among them, $\mathrm{MnOx}$ is particularly attractive because of their high catalytic activity, low cost, and minimum environmental impact. It has been reported that ORR catalytic activity of $\mathrm{MnOx}$ depends on its crystalline structure and oxidation state. ${ }^{4}$ It also depends sensitively on the surface area and the available active

Received: August 22, 2011

Revised: October 16, 2011

Published: November 03, 2011 

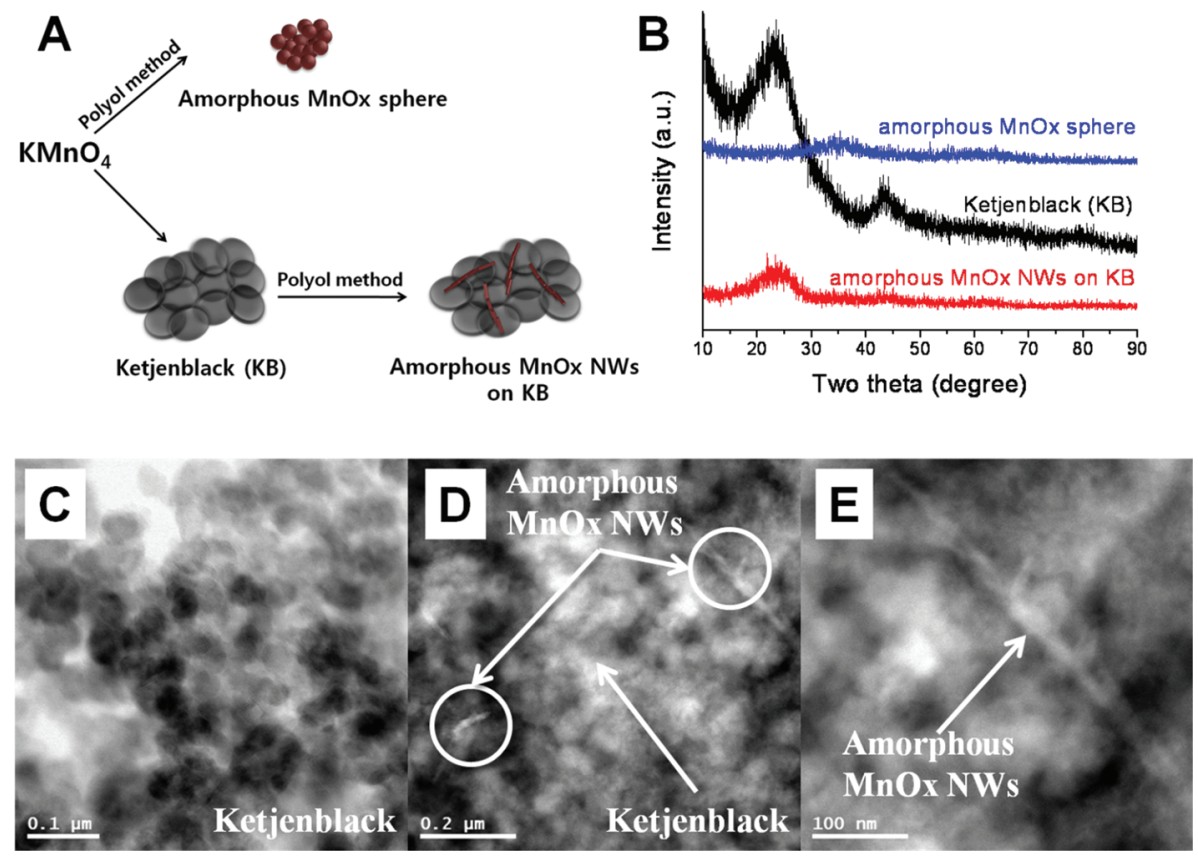

Figure 1. (A) Schematic description of amorphous $\mathrm{MnOx}$ particles (a-MnOx) and nanowires on Ketjenblack composite (a-MnOx NWs on $\mathrm{KB}$ ). (B) X-ray diffraction patterns of amorphous MnOx particle, Ketjenblack (KB), and amorphous MnOx nanowires on Ketjenblack composites. TEM images of (C) pristine Ketjenblack and (D) amorphous MnOx nanowires on Ketjenblack composites and (E) magnified TEM image of (D).

sites exposed to oxygen molecules. Thus, the use of an amorphous structure as catalysts could be more favorable over crystalline manganese oxide structures. Yang et al. reported that nanoporous amorphous manages oxides, synthesized via lowtemperature aqueous redox process, are efficient electrocatalysts for ORR in alkaline solutions, ${ }^{5}$ due mainly to high surface area and large concentration of lattice defects in the amorphous structures. They also showed that this oxide significantly facilitates a two-electron pathway in ORR. ${ }^{5}$

However, full utilization of $\mathrm{MnOx}$ as an efficient ORR catalyst is still limited by the low electrical conductivity of $\mathrm{MnOx} ;{ }^{6}$ to overcome this problem, conducting carbon materials, such as graphene and CNT, are usually used with $\mathrm{MnOx} .{ }^{7}$ To reduce the cost, commercially available, less expensive, conducting materials such as Ketjenblack can be used as an alternative way to prepare reliable ORR catalysts.

Here we report a simple approach to integration of amorphous $\mathrm{MnOx}$ nanowires with electrically conductive Ketjenblack carbon materials via a polyol method (hereafter denoted as a-MnOx NWs on KB) and the electrocatalytic properties of the composite electrode for ORR in a $\mathrm{Zn}$-air battery. In order to prepare a-MnOx NWs on $\mathrm{KB}$, ethylene glycol and potassium permanganate were used as the reducing agent and the precursor for manganese oxides, respectively. ${ }^{8}$ Permanganate ion can be reduced to amorphous manganese oxides by ethylene glycol under the mild condition. A solution based redox reaction for deposition of amorphous $\mathrm{MnOx}$ NWs onto the surface of Ketjenblack carbon in a carbon matrix is schematically illustrated in Figure 1A. Specifically, potassium permanganate, $\mathrm{KMnO}_{4}$, was mixed with pristine Ketjenblack carbon suspension in ethylene glycol under basic condition by adding a small amount of $0.5 \mathrm{M} \mathrm{NaOH}$, followed by heating to $80{ }^{\circ} \mathrm{C}$ and kept for $2 \mathrm{~h}$. The resulting amorphous manganese oxide on Ketjenblack composite was filtered and washed thoroughly with deionized water and ethanol, followed by drying in an oven at $60{ }^{\circ} \mathrm{C}$ for $12 \mathrm{~h}$. It is noted that the catalytic activity of $\mathrm{MnOx} / \mathrm{C}$ composite electrodes depends critically on the amount of $\mathrm{MnOx}$; for example, too much $\mathrm{MnOx}$ may decrease its overall electrical conductivity, thus deteriorating ORR activity. ${ }^{7} \mathrm{We}$ carried out controlled experiments to optimize the catalytic activity of the composite electrodes by systematically changing the contents of Mn precursor; our results suggested that electrodes with ca. $10 \mathrm{wt} \% \mathrm{MnOx}$ displayed the best ORR performance. A control experiment was also performed in the absence of Ketjenblack carbon under the same processing conditions (reaction temperatures and times), producing brown-black amorphous manganese oxides.

The X-ray diffraction (XRD) pattern from a sample of a-MnOx NWs on KB (Figure 1B) showed no distinct peaks (except those from ketjenblack), suggesting that the as-prepared $\mathrm{MnOx}$ was amorphous under this mild synthetic condition. TEM examination revealed that the amorphous $\mathrm{MnOx}$ on Ketjenbalck carbon had a nanowire morphology with a diameter of ca. $10 \mathrm{~nm}$ (Figure 1D,E), which was further confirmed with line mapping. (See Figure S2 in the Supporting Information). Since the NWs were obtained below $100{ }^{\circ} \mathrm{C}$, it is expected that they have many defects and rough surfaces. It is noted that the nanowire morphology of the amorphous $\mathrm{MnOx}$ on $\mathrm{KB}$ is very different from the particle shape of the amorphous $\mathrm{MnOx}$ without $\mathrm{KB}$ support (see Figure S3, Supporting Information), implying that the presence of $\mathrm{KB}$ matrix promoted the formation of $\mathrm{MnOx}$ nanowires. While many researchers have studied crystalline phases and morphologies of $\mathrm{MnOx}$ as ORR catalysts, little has been done on the effect of amorphous MnOx on ORR activity. To the best of our knowledge, this is the first time that amorphous $\mathrm{MnOx}$ nanowires (NWs) are grown on an amorphous template ( $\mathrm{KB}$ carbon) via a polyol method, allowing us to explore the effect of the amorphous structure of $\mathrm{MnOx}$ on ORR activities in an alkaline solution. We used amorphous $\mathrm{KB}$ as the template to produce amorphous $\mathrm{MnOx}$ because it has larger surface area with higher density surface defects than crystalline structures, potentially 

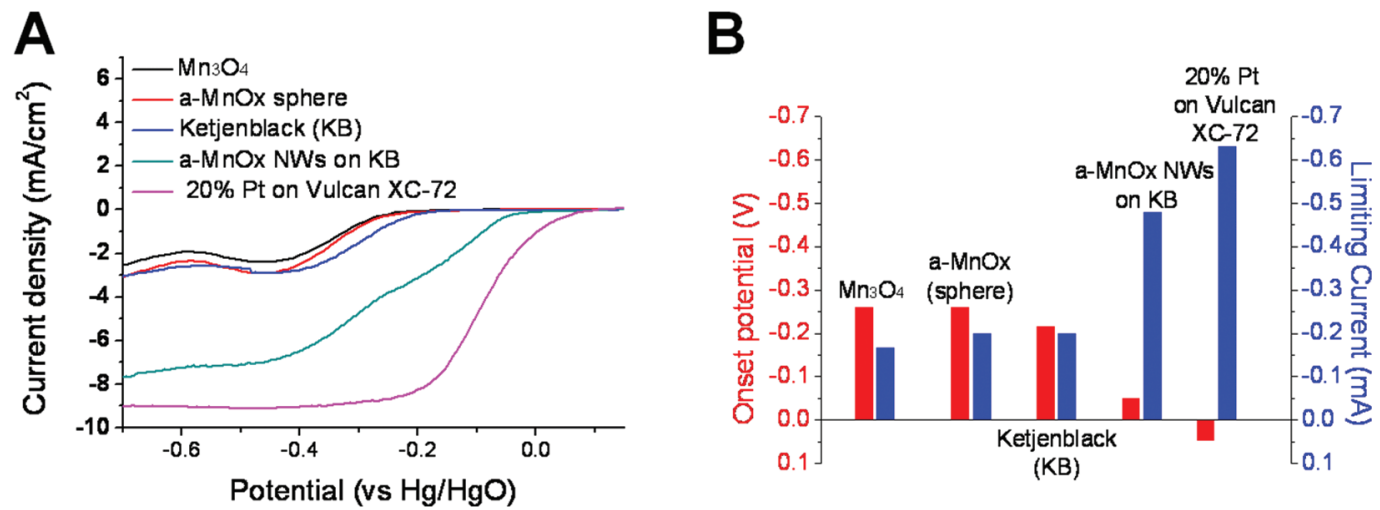

Figure 2. Rotating disk electrode ( $\mathrm{RDE}$ ) experiments of $\mathrm{Mn}_{3} \mathrm{O}_{4}$, amorphous $\mathrm{MnOx}$ particle (a-MnOx), Ketjenblack (KB), amorphous $\mathrm{MnOx}$ nanowires on Ketjenblack composites (a-MnOx NWs on KB), and 20\% Pt on Vulcan XC-72 (E-tek) under oxygen saturation condition at 3200 rpm; scan rate was $10 \mathrm{mV} / \mathrm{s} ; 0.10 \mathrm{M} \mathrm{KOH}$ was used as an electrolyte. Pt wire and $\mathrm{Hg} / \mathrm{HgO}$ were used as a counter and reference electrodes with a $3 \mathrm{~mm}$ diameter working electrode, respectively. Onset potential (red color) was measured at $-0.002 \mathrm{~mA}$ and limiting current (blue color) was measured at $-0.45 \mathrm{~V}$.

offering more active sites for oxygen reduction and higher ORR activity. Further, fabrication of the KB-templated amorphous structure is very inexpensive; it is a cost-effective approach for preparation of amorphous catalysts for metal-air and alkaline fuel cells.

To evaluate electrocatalytic activity for ORR of the a-MnOx NWs on $\mathrm{KB}$, rotating disk electrode ( $\mathrm{RDE}$ ) experiments were performed with two $\mathrm{MnOx}$ samples prepared at 80 and $160{ }^{\circ} \mathrm{C}$, pristine $\mathrm{KB}$, and a-MnOx NWs on $\mathrm{KB}$ composite (in Figure 2).

While the $\mathrm{MnOx}$ sample was amorphous when prepared at $80^{\circ} \mathrm{C}$, it turned to a crystalline phase of $\mathrm{Mn}_{3} \mathrm{O}_{4}$ when prepared at $160{ }^{\circ} \mathrm{C}$. (See Figure S4 in the Supporting Information.) The linear sweep voltammograms (Figure 2A,B) show that the onset potentials of the two samples are very similar, but the limiting current of the a- $\mathrm{MnOx}$ (prepared at $80^{\circ} \mathrm{C}$ ) is higher than that of the $\mathrm{Mn}_{3} \mathrm{O}_{4}$ sample (prepared at $160^{\circ} \mathrm{C}$ ). Because there is little difference in onset potential, the two samples have similar intrinsic ORR catalytic activity. Therefore, the improved limiting current of the a-MnOx sample may be attributed to the increased surface area or more adsorption sites for oxygen molecules. Brunaer, Emmet, and Taller (BET) surface areas of the a-MnOx $\left(80{ }^{\circ} \mathrm{C}\right)$ and the $\mathrm{Mn}_{3} \mathrm{O}_{4}\left(160{ }^{\circ} \mathrm{C}\right)$ are 273.5 and $97.8 \mathrm{~m}^{2} / \mathrm{g}$, respectively. Furthermore, although the limiting current for the pristine $\mathrm{KB}$ is similar to that for the a-MnOx, the onset potential of the $\mathrm{KB}$ is slightly more positive than that of the $\mathrm{a}-\mathrm{MnOx}$, implying that the intrinsic catalytic activity of the pristine $\mathrm{KB}$ is higher than that of the a-MnOx. Further, electrical conductivity of the MnOx may significantly impact the utilization of the ORR catalysts.

For the case of the a-MnOx NWs on $\mathrm{KB}$, surprisingly, the onset potential was shifted to a more positive direction and the limiting current was increased considerably, demonstrating that the ORR activity of this composite is far better than those of the pristine $\mathrm{KB}$ and the two $\mathrm{MnOx}$ samples (Figure $2 \mathrm{~B}$ ) in a weak basic solution $(0.1 \mathrm{M} \mathrm{KOH})$. Although carbon materials have high electrical conductivity, the catalytic activity for ORR is insufficient for practical applications. Clearly, our results indicate that the amorphous manganese oxide NWs in the composite electrodes significantly enhance the ORR activity.

However, the ORR activity of the a-MnOx NWs on KB composite appears to be less than that of a platinum based catalyst: $20 \mathrm{wt} \% \mathrm{Pt}$ on Vulcan XC-72. Although the BET surface area of the a-MnOx NWs on $\mathrm{KB}$ is $637 \mathrm{~m}^{2} / \mathrm{g}$, the surface area alone cannot account for the improved ORR activity. It is wellknown that the catalytic activity of a $\mathrm{MnOx} / \mathrm{C}$ composite depends critically on both the $\mathrm{MnOx}$ catalyst and the carbon support; the unique combination of $\mathrm{MnOx}$ and $\mathrm{KB}$ carbon may play a role in improving the catalytic activity; the synergetic effect of both components may contribute to the enhanced ORR activity of the composite. Further, on the basis of simple molecular orbital (MO) theory, the s and p orbitals of oxygen molecule should overlap with the d-orbital of a metal ion to break the $\mathrm{O}=\mathrm{O}$ bond and three possible configuration models (Griffith, Pauling, and Yeager's models ${ }^{9}$ ) have been proposed for oxygen molecule interaction with a metal ion in a complex. (See Figure S5 of the Supporting Information.) Since the energetics associated with each surface configuration may depend on surface orientation for crystalline phases of $\mathrm{MnOx}$, the amorphous $\mathrm{MnOx}$ may be energetically favorable for all three surface configurations, potentially providing more active sites that allow for oxygen adsorption with all possible surface configurations. Accordingly, we speculate that amorphous $\mathrm{MnOx} \mathrm{NW}$ structures may have potential for providing more active sites for ORR, resulting in enhanced catalytic activity for ORR. More theoretical and experimental characterizations and analyses of the atomistic and electronic structures of the composite electrodes are necessary to unravel the detailed mechanism of ORR processes on the $\mathrm{MnOx} / \mathrm{C}$ composite electrodes.

It is noted, however, that the RDE (half-cell) measurements for ORR catalysts are insufficient in predicting the performance of this composite in a practical zinc-air battery because the typical electrolyte concentration for the $\mathrm{RDE}$ measurements $(0.1 \mathrm{M} \mathrm{KOH})$ was much lower than that usually used in fullcell measurements $(6 \mathrm{M} \mathrm{KOH})$. For example, oxygen solubility in $0.1 \mathrm{M} \mathrm{KOH}$ is about 10 times higher than that in $6 \mathrm{M} \mathrm{KOH}$, which could considerably amplify the difference in ORR activity of the a-MnOx NWs on $\mathrm{KB}$ and $20 \% \mathrm{Pt}$ on Vulcan XC-72 under our RDE experimental condition $(0.1 \mathrm{M} \mathrm{KOH}) .{ }^{10}$ Therefore, it is necessary to characterize their ORR activity under the conditions similar to those for a practical zinc-air full cell using $6 \mathrm{M} \mathrm{KOH}$ electrolyte, as schematically shown in Figure 3A. The zinc-air battery is composed of an air electrode, a separator, and a zinc anode. Figure 3B shows that a peak power density of $\sim 190 \mathrm{~mW} / \mathrm{cm}^{2}$ was obtained from a cell based on an air cathode of a-MnOx NWs on 

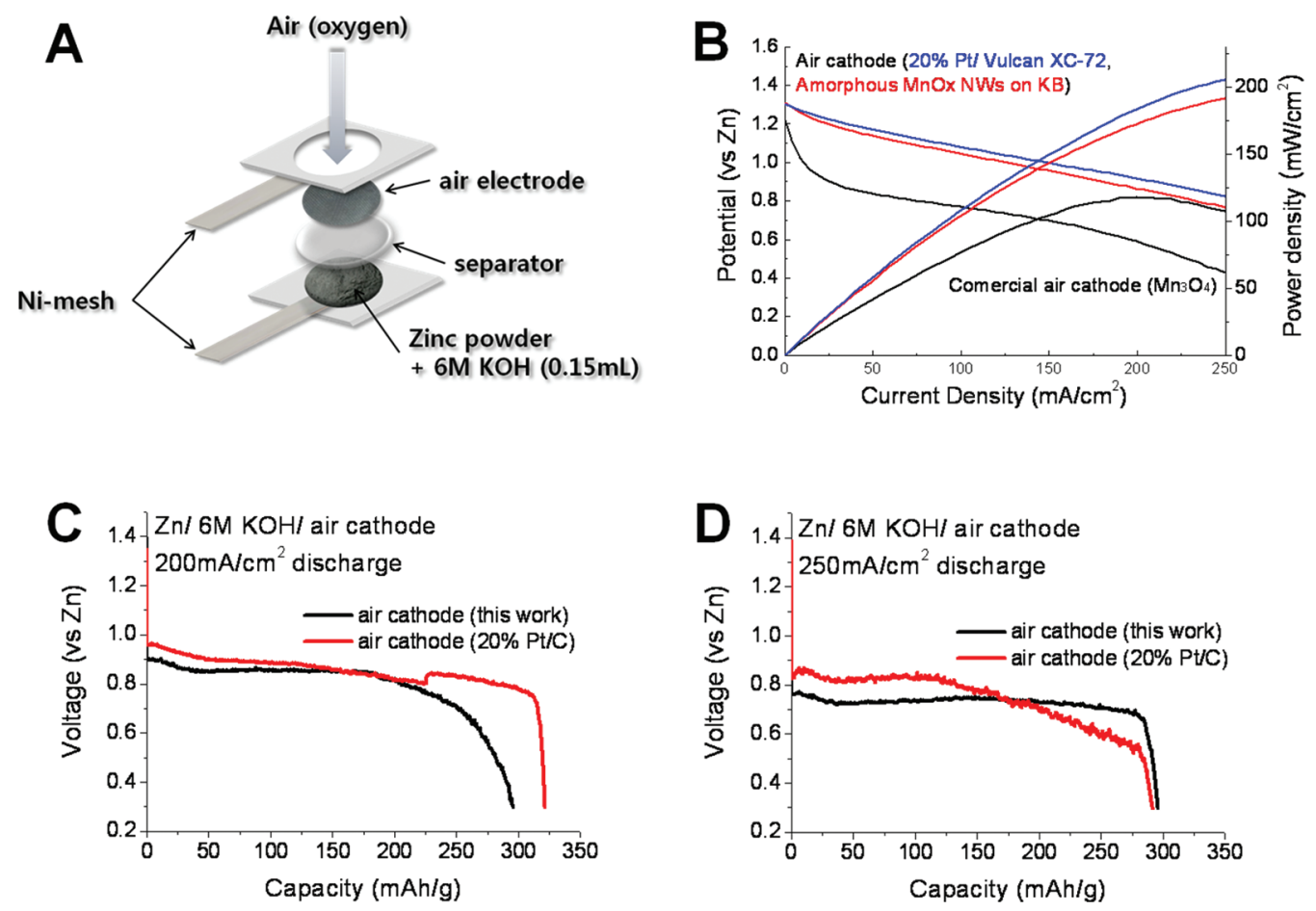

Figure 3. (A) A schematic of a zinc-air battery. (b) Polarization and (c, d) discharge curves at 200 and $250 \mathrm{~mA} / \mathrm{cm}^{2}$, respectively, of zinc-air full cells with different air electrodes: amorphous MnOx nanowires on Ketjenblack composites and 20\% Pt on Vulcan XC-72 (E-tek). A commercial air electrode (Meet) was used for comparison.

$\mathrm{KB}$ composite; the performance is much better than those obtained from cells based on a commercial air electrode with $\mathrm{Mn}_{3} \mathrm{O}_{4}$ catalysts (Meet Co.). Because the only difference between the test cells was the air electrode used in each zinc-air full cell assembly, the difference in overall electrochemical performance can be attributed to the difference in ORR activity of the air electrodes. The ORR activity of the a-MnOx NWs on $\mathrm{KB}$ composite electrode is very similar to that of a $20 \% \mathrm{Pt}$ on Vulcan carbon XC-72.

In addition to enhanced power density, the activation loss of the a-MnOx NWs on $\mathrm{KB}$ was also significantly reduced compared to that of the commercial electrode with crystalline $\mathrm{Mn}_{3} \mathrm{O}_{4}$, as seen from the $I-V$ curves. This result is also consistent with the RDE half-cell results (Figure 2). Panels $\mathrm{C}$ and D of Figure 3 show some typical galvanic discharge curves of a zinc-air full cell at 200 and $250 \mathrm{~mA} / \mathrm{cm}^{2}$, respectively. These discharging current densities are much higher than those reported in the literature for practical $\mathrm{Zn}-$ air cells (e.g., $10-20 \mathrm{~mA} / \mathrm{cm}^{2}$ ). ${ }^{11}$

The electrochemical performance of the as-prepared a- $\mathrm{MnOx}$ NWs on KB sample is very competitive to the commercial $20 \% \mathrm{Pt}$ on Vulcan XC-72 catalysts under even higher current densities, which is also consistent with the $I-V$ curves shown in Figure 3B. However, the capacity of the $\mathrm{Zn}$ - air cell (typically normalized by the weight of zinc) decreased with discharging rate (and lower than theoretical value of $820 \mathrm{mAh} / \mathrm{g}$ ) due to the formation of insulating $\mathrm{ZnO}$ on pristine $\mathrm{Zn}$ particles at high discharging current densities.

Conclusions. Amorphous manganese oxide ( $\mathrm{MnOx}$ ) nanowires grown on commercial Ketjenblack (KB) of high electrical conductivity and surface area display significantly enhanced catalytic activity toward oxygen reduction reaction in alkaline solutions. A $\mathrm{Zn}-$ Air battery based on a- $\mathrm{MnOx}$ on $\mathrm{KB}$ air cathode demonstrated a peak power density of $\sim 190 \mathrm{~mW} / \mathrm{cm}^{2}$, which is similar to the best performance of cells based on very expensive Pt catalysts (20\% Pt/Vulcan carbon). Both the KB and the a-MnOx nanowires contributed to the improved catalytic activity for ORR. In particular, amorphous $\mathrm{MnOx}$ NWs with high density surface defects potentially provide more active sites for oxygen adsorption, resulting in significantly enhanced ORR activity. The $\mathrm{MnOx} \mathrm{NWs} / \mathrm{KB}$ composite is a very promising electrode for ORR in alkaline solutions.

Experimental Section. Preparation of Amorphous Manganese Oxide Nanowires on Ketenblack Composites ( $a-M n O x N W s / K B)$. A $0.28 \mathrm{~g}$ portion of Ketjenblack (EC-300J) was dispersed in $20 \mathrm{~mL}$ of ethylene glycol (Sigma Aldrich), which was stirred vigorously with a magnetic bar, and then $0.2 \mathrm{~mL}$ of $0.5 \mathrm{M} \mathrm{NaOH}$ (Samchun chemical) and $0.094 \mathrm{mmol}$ of $\mathrm{KMnO}_{4}$ (Sigma Aldrich) were added to this black suspension. This round-bottom flaks was transferred to reflux condenser, heated up to $80{ }^{\circ} \mathrm{C}$, and sustained for $2 \mathrm{~h}$. The black powder was filtered and washed with distilled water and ethanol and dried at $60{ }^{\circ} \mathrm{C}$ for $12 \mathrm{~h}$. For comparison, amorphous $\mathrm{MnOx}$ was also prepared using the same procedure but without the addition of Ketjenblack.

Material Characterization. The material morphology was examined using a SEM (Nanonova 230, FEI) operating at $10 \mathrm{kV}$ and TEM (JEOL JEM-2100F) operating at $200 \mathrm{kV}$. Powder analysis was performed using an X-ray diffractometer (XRD) (D/Max2000, Rigaku).

Preparation of Catalysts Paste for Rotating Disk Electrode. Catalyst paste was prepared by ultrasonically mixing $6.0 \mathrm{mg}$ of asprepared sample with $3.0 \mathrm{~mL}$ of pure deionized water for $1 \mathrm{~h}$ in order to make a homogeneous suspension. Then, $3 \mu \mathrm{L}$ of the prepared catalytic paste was transferred to the surface of a glassy carbon electrode of $3 \mathrm{~mm}$ diameter using a micropipet. 
Finally, the ink was allowed to dry for 10 min under vacuum at room temperature to form a thin catalyst film on a glassy carbon electrode as a working electrode.

Rotating Disk Electrode (RDE) Experiments. All half-cell experiment for ORR using a rotating disk electrode (RDE) (ALS Co., Ltd.) was carried out under the same conditions where $\mathrm{Pt}$ wire and $\mathrm{Hg} / \mathrm{HgO}$ were used as a counter and reference electrodes, respectively; $0.10 \mathrm{M} \mathrm{KOH}$ was used as an electrolyte; pure oxygen gas (99.9\%) was purged for $30 \mathrm{~min}$ before each RDE experiment to make the electrolyte saturated with oxygen. Electrochemical characterization of as-prepared catalysts were conducted using a single potentiostat (Ivium) with a scan rate of $10 \mathrm{mV} / \mathrm{s}$ and potential range from 0.15 to $-0.7 \mathrm{~V}$.

Preparation of an Air Electrode. All air electrodes used in this zinc-air full cell test were prepared with a fixed composition (in weight); activated carbon (Darco G-60A, Sigma Aldrich) was 62 wt $\%+$ poly(tetrafluoroethylene) (PTFE) binder 30 wt \% (60 wt \% PTFE emulsion in water, Sigma Aldrich) + as-prepared catalysts was $8 \mathrm{wt} \%$. After sonicating each material in pure deionized water for $1 \mathrm{~h}$, each suspension was then mixed ultrasonically for $1 \mathrm{~h}$ to form a homogeneous suspension. Excess water was removed by filtering the homogeneous suspension, and then the slurry was dried at $60{ }^{\circ} \mathrm{C}$. By adding isopropyl alcohol to dried black powder, air electrodes were manufactured via a kneading and rolling process to make the desired thickness of air cathode. Finally, Ni-foam as a current collector was attached to the back side of the air electrode. The thickness of all air cathodes was $600 \mu \mathrm{m}$ to the minimize thickness factor of the electrode to overall cell performance.

Zinc-Air Full Cell Assembly. For the zinc-air full cell test, homemade zinc-air single cells were used in these experiments. One gram of zinc powder (Umicore) was used as the anode electrode. Nylon net filters (Millipore) were used as separators. A 16-pi Air electrode was used as the cathode electrode. The galvanodynamic experiment was carried out with multichannel potentiostat (WBCS 3000, WonA Tech, Korea) with current densities varied from 0 to $250 \mathrm{~mA} / \mathrm{cm}^{2}$ to characterize cell performance. The galvano discharge curves of zinc-air cells were recorded at 200 and $250 \mathrm{~mA} / \mathrm{cm}^{2}$, respectively.

\section{ASSOCIATED CONTENT}

S Supporting Information. Additional figures showing rates in general metal-air battery, TEM and SEM images, $\mathrm{X}$-ray diffraction patterns of amorphous $\mathrm{MnOx}$ particles, and possible configuration of oxygen interaction with a metal. This material is available free of charge via the Internet at http:// pubs.acs.org.

\section{AUTHOR INFORMATION}

\section{Corresponding Author}

*E-mail: meilin.liu@mse.gatech.edu; jpcho@unist.ac.kr.

\section{ACKNOWLEDGMENT}

This work was supported by the World Class University (WCU) program supported by National Research Foundation (NRF) and the Ministry of Education, Science and Technology (MEST) of Korea. Also, this research was supported by the MKE (The Ministry of Knowledge Economy), Korea, under the ITRC (Information Technology Research Center) support program supervised by the NIPA (National IT Industry Promotion Agency) (NIPA-2011-C1090-1100-0002).

\section{REFERENCES}

(1) Lee, J.-S.; Tai Kim, S.; Cao, R.; Choi, N.-S.; Liu, M.; Lee, K. T.; Cho, J. Metal-Air Batteries with High Energy Density: Li-Air versus $\mathrm{Zn}-$ Air. Adv. Energy Mater. 2011, 1 (1), 34-50.

(2) (a) Lee, K.; Kim, M.; Kim, H. Catalytic nanoparticles being facetcontrolled. J. Mater. Chem. 2010, 20 (19), 3791-3798. (b) Lim, B.; Jiang, M.; Camargo, P. H. C.; Cho, E. C.; Tao, J.; Lu, X.; Zhu, Y.; Xia, Y. Pd-Pt Bimetallic Nanodendrites with High Activity for Oxygen Reduction. Science 2009, 324 (5932), 1302-1305. (c) Stamenkovic, V. R.; Fowler, B.; Mun, B. S.; Wang, G.; Ross, P. N.; Lucas, C. A.; Markovic, N. M. Improved Oxygen Reduction Activity on $\mathrm{Pt} 3 \mathrm{Ni}(111)$ via Increased Surface Site Availability. Science 2007, 1135941.

(3) Chen, Z.; Higgins, D.; Yu, A.; Zhang, L.; Zhang, J. A review on non-precious metal electrocatalysts for PEM fuel cells. Energy Environ. Sci. 2011, DOI:10.1039/B8-8370C.

(4) (a) Cao, Y. L.; Yang, H. X.; Ai, X. P.; Xiao, L. F. The mechanism of oxygen reduction on $\mathrm{MnO}_{2}$-catalyzed air cathode in alkaline solution. J. Electroanal. Chem. 2003, 557, 127-134. (b) Mao, L.; Sotomura, T.; Nakatsu, K.; Koshiba, N.; Zhang, D.; Ohsaka, T. Electrochemical Characterization of Catalytic Activities of Manganese Oxides to Oxygen Reduction in Alkaline Aqueous Solution. J. Electrochem. Soc. 2002, 149 (4), A504-A507. (c) Cheng, F.; Su, Y.; Liang, J.; Tao, Z.; Chen, J. $\mathrm{MnO}_{2^{-}}$ Based Nanostructures as Catalysts for Electrochemical Oxygen Reduction in Alkaline Media. Chem. Mater. 2009, 22 (3), 898-905. (d) Lima, F. H. B.; Calegaro, M. L.; Ticianelli, E. A. Investigations of the catalytic properties of manganese oxides for the oxygen reduction reaction in alkaline media. J. Electroanal. Chem. 2006, 590 (2), 152-160. (e) Xiao, W.; Wang, D.; Lou, X. W. Shape-Controlled Synthesis of $\mathrm{MnO}_{2}$ Nanostructures with Enhanced Electrocatalytic Activity for Oxygen Reduction. J. Phys. Chem. C 2009, 114 (3), 1694-1700.

(5) Yang, J.; Xu, J. J. Nanoporous amorphous manganese oxide as electrocatalyst for oxygen reduction in alkaline solutions. Electrochem. Commun. 2003, 5 (4), 306-311.

(6) (a) Kim, H.; Popov, B. N. Synthesis and Characterization of $\mathrm{MnO}_{2}$-Based Mixed Oxides as Supercapacitors. J. Electrochem. Soc. 2003, 150 (3), D56-D62. (b) Zhang, L. L.; Wei, T.; Wang, W.; Zhao, X. S. Manganese oxide-carbon composite as supercapacitor electrode materials. Microporous Mesoporous Mater. 2009, 123 (1-3), 260-267.

(7) Lee, J.-S.; Lee, T.; Song, H.-K.; Cho, J.; Kim, B.-S. Ionic liquid modified graphene nanosheets anchoring manganese oxide nanoparticles as efficient electrocatalysts for Zn-air batteries. Energy Environ. Sci. 2011, 4 (10), 4148-4154.

(8) Ragupathy, P.; Park, D. H.; Campet, G.; Vasan, H. N.; Hwang, S.-J.; Choy, J.-H.; Munichandraiah, N. Remarkable Capacity Retention of Nanostructured Manganese Oxide upon Cycling as an Electrode Material for Supercapacitor. J. Phys. Chem. C 2009, 113 (15), 6303-6309.

(9) (a) Griffith, J. S. On the Magnetic Properties of Some Haemoglobin Complexes. Proc. R. Soc. London, Ser. A 1956, 235 (1200), 23-36. (b) Pauling, L. Nature of the Iron-Oxygen Bond in Oxyhaemoglobin. Nature 1964, 203 (4941), 182-183. (c) Yeager, E. Recent Advances in the Science of Electrocatalysis. J. Electrochem. Soc. 1981, 128 (4), 160C-171C. (d) Hanson, L. K.; Hoffman, B. M. Griffith model bonding in dioxygen complexes of manganese porphyrins. J. Am. Chem. Soc. 1980, 102 (14), 4602-4609.

(10) Davis, R. E.; Horvath, G. L.; Tobias, C. W. The solubility and diffusion coefficient of oxygen in potassium hydroxide solutions. Electrochim. Acta 1967, 12 (3), 287-297.

(11) Cheng, F.; Shen, J.; Peng, B.; Pan, Y.; Tao, Z.; Chen, J. Rapid room-temperature synthesis of nanocrystalline spinels as oxygen reduction and evolution electrocatalysts. Nat. Chem. 2011, 3 (1), 79-84. 